\title{
Dimensões Normativas do Individualismo e Coletivismo: É Suficiente a Dicotomia Pessoal vs. Social?
}

\author{
Valdiney V. Gouveia ${ }^{12}$ \\ Josemberg M. de Andrade \\ Taciano Lemos Milfont \\ Fabiana Queiroga \\ Walberto Silva dos Santos \\ Universidade Federal da Paraíba
}

\begin{abstract}
Resumo
Previamente tem sido sugerida a relação do individualismo e coletivismo com os valores humanos. Não obstante, são escassas as pesquisas que visam comprová-la empiricamente. O presente estudo objetivou conhecer os valores humanos que melhor descrevem as dimensões destes construtos (individualismo vertical, individualismo horizontal, protoindividualismo, individualismo expressivo, coletivismo vertical e coletivismo horizontal). Participaram 304 pessoas, membros da população geral e estudantes do ensino médio e universitário. A maioria foi do sexo feminino (62,5\%), com idade média de 29 anos. Estes responderam a Escala Multi-Fatorial de Individualismo e Coletivismo e o Questionário dos Valores Básicos, além de perguntas sóciodemográficas. Verificou-se que o individualismo pode ser melhor caracterizado pelos valores pessoais, enquanto que o coletivismo expressa uma ênfase nos valores sociais. No que se refere às dimensões do individualismo e coletivismo, estas foram correlacionadas de modo diferenciado com certos valores básicos, permitindo identificar um tipo específico de orientação social. Estes resultados foram discutidos com base na literatura da Psicologia Social Trans-Cultural, evidenciando-se sua importância para compreender $\mathrm{o}$ individualismo e coletivismo.

Palavras-chave: Valores; coletivismo; individualismo; protoindividualismo.
\end{abstract}

\section{Normative Dimensions of the Indivivualism and Collectivism: Is the Dichotomy Personal vs. Social Sufficient?}

\begin{abstract}
The relationship between individualism/collectivism constructs with human values has been previously suggested. However, the studies that try to empirically valiate this relationship are scarce. Thus, this study aimed to identify the human values that best describe the dimensions of these constructs (vertical individualism, horizontal individualism, prothoindividualism, expressive individualism, vertical collectivism and horizontal collectivism). Three hundred and four subjects, members of the general population, as well as high school and undergraduate students, took part in the study. Most of them were female (62.5\%), with a mean age of 29 years old. They answered the Mult-Factorial Individualism and Collectivism Scale, and the Basic Values Questionnaire, a part from sociodemographic questions. The results indicated that individualism may be best characterized by personal values, while the collectivism expresses an emphasis on social values. Regarding specific dimensions of individualism and collectivism, they were differently correlated with certain basic values, allowing to identify specific types of this specific social orientation. These results were discussed based on Cross-Cultural Social Psychology literature, showing their importance for understanding the individualism and collectivism constructs.

Keywords: Values; collectivism; individualism; prothoindividualism.
\end{abstract}

A partir do paradigma do individualismo e coletivismo foram formados dois núcleos temáticos com características próprias: o normativo e o relacional (Kagitçibasi, 1997). O primeiro enfatiza os valores, as atitudes e as crenças, enquanto

\footnotetext{
${ }^{1} \mathrm{O}$ presente estudo compreende parte de um projeto integrado, financiado pelo CNPq (Proc. CNPq - 520521/99-4). Os autores agradecem a esta instituição.

${ }^{2}$ Endereço para correspondência: Universidade Federal da Paraíba, CCHLA, Depto. de Psicologia, Programa de Pós-Graduação em Psicologia Social, 58051 900. João Pessoa, PB.E-mail:vgouveia@cchla.ufpb.br/vvgouveia@uol.com.br
}

que o segundo contempla principalmente os aspectos da interação interpessoal, as relações intra e inter-grupais e a auto-imagem. O presente estudo, enfocando a perspectiva da Psicologia Social Trans-Cultural, centra-se no aspecto normativo do individualismo e coletivismo, tendo como objetivo conhecer os valores humanos que melhor descrevem cada tipo de orientação com o fim de propor uma estrutura valorativa que sirva de referência para pesquisas futuras.

Ao menos de forma implícita, as orientações individualista e coletivista sempre estiveram presentes nos estudos dos valores humanos (Gouveia \& Vidal, 1998). No 
entanto, embora se fale em valores individualistas e coletivistas, tem-se pouca informação disponível sobre os aspectos convergentes dos modelos teóricos que envolvem estes construtos (Gouveia, 2001). Em uma série de pesquisas tem-se procurado definir os valores característicos de culturas individualistas e coletivistas (ver Schwartz, 1990; Triandis, McCusker \& Hui, 1990). A partir do modelo de Schwartz (1990, 1994), que permite identificar a priori valores individuais, coletivos e mistos, é possível encontrar na literatura um grande número de publicações que os diferenciam. A maioria destas, porém, está baseada em procedimentos estritamente empíricos ou circunstanciais, centrando-se em especular quais valores estão mais relacionados com uma ou outra orientação (ver Gouveia \& Vidal, 1998). A seguir, tem-se uma descrição mais detalhada destes construtos.

\section{O Individualismo e o Coletivismo}

Em recentes publicações, Triandis $(1993,1995,1996)$ define o individualismo e o coletivismo como sindromes culturais: consistem em compartilhar atitudes, crenças, normas, papéis e definições do $e$, sendo os valores dos membros de cada cultura organizados de forma coerente em torno de um tema. Individualistas e coletivistas estão prontos para perseguir diferentes tipos de objetivos. Em culturas predominantemente coletivistas, espera-se como mais provável um modo de vida mais centrado na sociedade; por outro lado, em culturas individualistas, contempla-se uma ênfase no indivíduo (Gouveia \& Vidal, 1998; Markus \& Kitayama, 1991).

Pode-se dizer que o individualismo expressa uma tendência ao êxito, à valorização da própria intimidade. Neste tipo de orientação, o indivíduo está por cima dos grupos em todos os aspectos; as relações pessoais são mais freqüentes, porém contratuais. Este padrão implica geralmente em uma separação dos familiares e uma ruptura com os ancestrais, dando-se ênfase ao presente, com um grau elevado de complexidade social (Gouveia, Clemente \& Vidal, 1998). Embora o sujeito orientado pelo individualismo possa se definir como membro de muitos grupos, estes não são exatamente os de pertença incondicional; este tipo de grupo está restringido a sua família nuclear. Alguém que é individualista pensa, sente e atua segundo seus próprios interesses, importando em menor medida o contexto social em que se encontra (Gouveia, 2001).

O coletivismo, por sua vez, define uma tendência à cooperação e ao cumprimento com os demais. O grupo do qual a pessoa faz parte importa mais do que a própria pessoa. Os grupos de pertença podem ser reduzidos em número e grandes em extensão (por exemplo, a família com todos os seus ascendentes e descendentes). Internamente nos grupos, tais indivíduos mantêm fortes relações entre si e podem compartilhar os mesmos interesses. O conflito dentro dos grupos é algo que não é esperado (Gouveia \& cols., 1998). Cada pessoa dentro do grupo é valorizada como um fim em si; o indivíduo atua levando em consideração o contexto e as demais pessoas com as quais compartilha o sentido de pertença grupal (ver Gouveia, 2001).

Em outras palavras, culturas individualistas se caracterizam por valorizar a autonomia do indivíduo e sua independência emocional dos grupos sociais; já as coletivistas valorizam a tradição herdada e a dependência emocional dos grupos, pois o indivíduo é um ser que adquire sentido como parte de uma coletividade (Triandis, 1995). O individualismo estaria relacionado com valores que enfatizam a autonomia da pessoa, enquanto que o coletivismo o faria com valores que enfatizam a dependência do indivíduo em relação ao endogrupo (grupo de pertença). Isso implicaria que as pessoas seriam individualistas ou coletivistas, segundo os tipos de valores que dão mais importância. Schwartz (1990), por sua vez, critica esta posição dicotômica, afirmando, a partir de estudos empíricos, que alguns valores podem servir a interesses individuais e coletivos concomitantemente, propondo uma estrutura bidimensional dos valores.

Triandis faz parte do grupo de pesquisadores que está mais diretamente relacionado com o tema em questão. Este autor recuperou seus estudos dos anos 1970 sobre tradição e modernidade e ajustou ao novo paradigma da Psicologia Trans-Cultural: individualismo e coletivismo (Kagitçibasi \& Berry, 1989). Provavelmente por esta razão, esteve durante anos tratando estes construtos como bidimensionais, que de início esperava-se que fossem orientações opostas (Ros \& Gómez, 1997), apesar dos estudos empíricos sugerirem uma estrutura multi-fatorial. Se antes da obra de Triandis se falava em individualismo-coletivismo como uma única dimensão bipolar, a partir desta, passou-se a pensar em individualismos e coletivismos. Este autor não só reconheceu que não se tratava de uma única dimensão bipolar, senão que poderiam assumir distintos fatores de um ou outro construto.

Assim, passou-se a reconhecer que não necessariamente individualismo e coletivismo são pólos opostos. As pessoas são um pouco de cada um, sendo, muitas vezes, o contexto, a situação imediata, que vai definir o estilo mais apropriado de comportamento (Triandis, 1995; Triandis, Chen \& Chan, 1998). Em todo caso, espera-se que predomine uma destas orientações, não se podendo ignorar a possibilidade de coexistência de ambas (Schwartz, 1990). Por exemplo, Sinha e Tripathi (1994) concluíram que na Índia encontra-se uma mistura de individualismo e coletivismo; este tipo de 
orientação seria condicionado pelos diversos tipos de valores compartilhados nessa sociedade.

Na primeira metade dos anos 1990, Triandis (1995) chegou à máxima evolução dos seus estudos ao recuperar a clássica dimensão Distância de Poder (Hofstede), também interpretada como Hierarquia Social (Schwartz), identificando dois atributos-chave para diferenciar os principais tipos de individualismo e coletivismo: horizontal e vertical.

O atributo horizontal sugere que as pessoas são similares na maioria dos aspectos, especialmente no status. No caso do individualismo, em função da alta liberdade e igualdade que estas experimentam, constrói-se um eu independente, mas não diferente dos demais membros da sua cultura. Em outras palavras, as pessoas que se orientam pelo individualismo horizontal querem ser distintas dos grupos. Em relação ao coletivismo, contempla-se uma baixa liberdade, porém alta igualdade, explicando o motivo de um eu interdependente e compartilhado com os demais membros da sociedade. Assim, as pessoas se vêem como sendo similares às outras, enfatizam objetivos comuns com os outros, mas, todavia, não são submetidas facilmente à autoridade.

O conceito vertical põe ênfase em aceitar a desigualdade e privilegiar a hierarquia. Para os individualistas, isto se reflete em um eu independente e diferente dos demais; aceita-se a baixa igualdade ao passo que é dada máxima importância ao sentido de liberdade, definindo uma típica democracia de mercado. As pessoas que seguem esta orientação querem ser distintas, adquirindo status social. Fazem isso geralmente em competições com os outros. No caso dos coletivistas, traduz-se no sentido de servir aos outros, fazer sacrifícios em benefício do seu próprio grupo de pertença e cumprir suas obrigações impostas como normas sociais. Contempla-se um en interdependente, mas diferente dos demais, possivelmente devido ao baixo sentido de liberdade e igualdade (ver Triandis \& Gelfand, 1998).

Triandis (1995) reconhece que podem existir outras facetas destes construtos, mas as apresenta como sendo as principais. Para cada tipo de orientação social em questão, este autor identifica uma característica que mais adequadamente descreve a pessoa que a adota: Individualismo horizontal: Único; Individualismo vertical: Orientado ao êxito; Coletivismo horizontal: Cooperativo; e Coletivismo vertical: Cumpridor.

Esta nova estrutura multi-fatorial, sem a condição de oposição entre individualismo e coletivismo, tem sido comprovada principalmente em culturas norte-americanas (Singelis, Triandis, Bhawuk \& Gelfand, 1995; Triandis \& Gelfand, 1998). Gouveia, Clemente e Espinosa (no prelo) realizaram uma replicação do estudo de Singelis e colaboradores (1995) na Espanha, chegando a resultados bastante similares aos que estes pesquisadores encontraram.
Ademais, demonstraram que a tipologia de Triandis é útil para explicar alguns indicadores de relação interpessoal (Ex.: grau das amizades, identificação com os membros de endogrupos etc.). Não se encontraram dados sobre a adequação deste modelo no Brasil.

Além dos atributos já mencionados, Triandis (1995) identifica o protoindividualismo. Este seria importante para caracterizar culturas com claras desigualdades sociais e econômicas, como no caso do Brasil. Esta dimensão tem como atributo-chave ser batalhador. Sugere-se que seja típico das sociedades em que as pessoas realizam suas atividades com independência das demais, sendo os caçadores e pescadores personagens representativos desta orientação. Este tipo de individualismo parece ser uma forma de sobreviver, não de se relacionar com outras pessoas (Gouveia, 1998). Não se descarta também a importância que o construto individualismo expressivo possa ter neste contexto. Parsons (1959/1976) o identifica como típico de HispanoAmérica: enfoca uma tendência a dar maior importância aos relacionamentos, principalmente no âmbito familiar e da comunidade local, desestimando as orientações instrumentais. Este tem como atributo-chave ser expressivo.

\section{Valores Humanos: A Dicotomia Pessoal vs. Social}

Os valores humanos são um tema bastante estudado, pois possuem um papel importante no processo seletivo das ações humanas (Rokeach, 1973). Nas definições dos valores sempre aparecem evidentes determinados atributos (desejáveis, resistentes à modificação etc.), refletindo um certo consenso. No entanto, a fonte da sua origem não é geralmente muito precisa, embora sempre esteja presente a noção de necessidades humanas (Inglehart, 1991; Rokeach, 1973; Schwartz \& Bilsky, 1990). Apesar de terem sido muitas as contribuições teóricas ao tema dos valores (Braithwaite \& Scott, 1991), possivelmente as mais reconhecidas na Psicologia se devem a Milton Rokeach e Shalom H. Schwartz, sendo seus modelos resumidos a seguir:

- Milton Rokeach. Este autor foi o responsável por definir um espaço nas ciências humanas e sociais para o estudo dos valores. Seu modelo representa a primeira tentativa clara de diferenciar os valores de outros conceitos, como as atitudes, os traços de personalidade, propondo também uma medida exclusiva e objetiva dos valores humanos, entendidos como prioridades axiológicas que guiariam a vida das pessoas. Concebeu os valores como "uma crença duradoura de que um modo específico de comportamento ou estado último de existência é pessoal ou socialmente preferível a um modo de comportamento ou estado final de existência oposto ou inverso" (Rokeach, 1973, p. 5).

Rokeach (1973) assume que existe um número reduzido de valores, os quais seriam universais, variando apenas seu 
grau de importância para as pessoas, e sendo organizados em um sistema estruturado. Seguindo estas premissas, identificou um conjunto de 36 valores, divididos em dois grupos: instrumentais (Ex.: salvação, um mundo em paz) e terminais (Ex.: inteligente, responsável). Embora os valores apresentem outras funções, Rokeach destaca a que diz respeito à sua base motivacional. Os valores servem como um padrão, capaz de guiar o comportamento de várias formas e sob diversas condições, possibilitando também a resolução de conflitos e tomadas de decisões.

- Shalom H. Schwartz: O modelo teórico deste autor é uma herança daquele previamente resumido. Tomando como base a literatura sobre este tema, Schwartz e Bilsky $(1987,1990)$ elaboraram uma definição integradora dos valores, considerando-os como conceitos ou crenças, capazes de expressar estados finais de existência ou comportamentos desejáveis, que transcendem situações específicas, guiam a seleção e avaliação de comportamentos e eventos e são classificados por sua importância relativa. Segundo Schwartz e seus colaboradores, tais valores são derivados de três requerimentos humanos universais, a saber: a) as necessidades dos indivíduos enquanto organismos biológicos, b) a necessidade de interação social coordenada e c) a necessidade de sobrevivência e bem-estar dos grupos. Portanto, parece evidente a natureza motivacional dos valores, organizados por estes autores em 10 tipos de valores: autodireção, estimulação, hedonismo, realização, poder, benevolência, conformidade, tradição, seguranşa e universalismo.

Segundo Schwartz (1990, 1992), em função da importância atribuída aos diferentes tipos motivacionais, forma-se uma estrutura de valores que orienta as atitudes, as opiniões e os pensamentos do ser humano. Em última instância, tal estrutura dá sentido aos interesses que são prioritários na vida das pessoas, sendo estes classificados como individuais (autodireção, estimulação, realização, hedonismo e poder), coletivos (benevolência, conformidade e tradição) ou mistos (segurança e universalismo). Isso revela uma estrutura de compatibilidade e conflito, que faz com que as pessoas que dão importância a poder tendam a faze-lo também em relação à realização; esta mesma pessoa daria pouca importância a valores de tradição.

Este modelo tem sido aplicado com bastante freqüência para explicar uma variedade de condutas, demonstrando existir uma curva sinusoidal que permite predizer o padrão de correlação dos valores humanos com, por exemplo, desejabilidade social (Schwartz, Verkasalo, Antonovsky \& Sagiv, 1997) e religiosidade (Schwartz \& Huismans, 1995). Neste sentido, comparada com a teoria de Rokeach (1973), a que propõe S. H. Schwartz representa um avanço; compreende uma tentativa de solucionar antigos problemas, como a dificuldade de trabalhar com itens individuais.
Schwartz (1992) propõe considerar a soma dos itens que conformam cada tipo motivacional, o que resultaria em índices compostos de valores.

Apesar do antes comentado, cabe reforçar aqui a correspondência das teorias destes autores. Rokeach e Schwartz partiram de uma mesma lista de valores, a que o primeiro assumiu como intuitiva. Schwartz contribuiu para este campo de estudo ao propor um modelo mais estruturado, aprimorando as idéias de Rokeach, como a que se refere à estrutura dos valores humanos, que inicialmente eram classificados rudimentarmente em terminais e instrumentais. Além do mais, a ênfase de Schwartz foi muito forte na base motivacional dos valores, embora ele nunca tenha apresentado uma teoria que pudesse integrar sua lista de valores (Gouveia, 1998; Molpeceres, 1994). A propósito, o próximo modelo representa uma tentativa nesta direção, propondo uma classificação dos valores que considera diretamente a dicotomia pessoal vs. social, como se descreve.

- Modelo dos Valores Humanos Básicos. Recuperando as teorias existentes sobre os valores humanos e dando ênfase a sua base motivacional, Gouveia (1998) propôs um conceito alternativo dos valores, como segue: "categorias de orientação consideradas como desejáveis, baseadas nas necessidades humanas e nas pré-condições para satisfazêlas, adotadas por atores sociais, podendo variar quanto à sua magnitude e aos elementos que as definem" (p. 293). Para identificar cada valor básico, este autor considerou o conjunto de necessidades de Maslow (1954/1970), assumindo que tais valores conformam um sistema fundamentado em três critérios de orientação, cada um dividido em duas funções psicossociais, como segue:

Valores Pessoais. Dá-se prioridade aos próprios benefícios. $\mathrm{Na}$ tipologia de Rokeach (1973), compreendem os valores de foco intra-pessoal, centrados na própria pessoa. Dividem-se nas seguintes funções psicossociais: a) experimentação: descobrir e apreciar novos estímulos, enfrentar situações limite, assim como buscar satisfação sexual (emoção, estimulação, prazere sexuał); e b) realização: ressalta-se a realização, o sentimento de ser importante e poderoso, ser uma pessoa com identidade e espaço próprio. Quem assume este padrão de valores costuma manter relações pessoais contratuais, com o fim de obter benefícios (autodireção, êxito, poder, prestígio eprivacidade).

Valores Centrais. Estes figuram entre e são compatíveis com os valores pessoais e sociais. Suas funções psicossociais são: a) existência: expressa uma preocupação por garantir a própria existência orgânica (estabilidade pessoal, saúde e sobrevivência); a ênfase não é sobre a individualidade pessoal, mas sobre a existência individual; e b) suprapessoal: define a situação social por excelência em que a pessoa pode 
obter seus objetivos independentemente de sua condição social ou grupo afiliativo; descreve alguém maduro, com preocupações menos materiais (beleza, conhecimento, justiça social e maturidade). Os valores desta função enfatizam a importância de todas as pessoas, não exclusivamente dos indivíduos que compõem o grupo de pertença.

Valores Sociais. Quem assume o padrão de valores sociais se orienta em direção aos demais. Seu comportamento pode traduzir o desejo de se sentir considerado, assegurar sua aceitação e integração no seu grupo, ou manter um nível indispensável de harmonia entre os diversos atores sociais de um contexto específico. Esta orientação de valores se divide nas seguintes funções psicossociais: a) normativa: ênfase na vida social, na busca de estabilidade do grupo, nos comportamentos socialmente corretos e no respeito pelos símbolos e padrões culturais que prevaleceram durante anos; estima-se a ordem acima de qualquer outra coisa (obediência, ordem social, religiosidade e tradição); e b) interacional: focaliza-se a atenção nas demais pessoas. Sua especificidade enquanto conjunto fundamenta-se no interesse por se sentir querido, ter amizades verdadeiras e uma vida social (afetividade, apoio social, convivencia e honestidade).

Em resumo, os valores humanos têm sido classificados de diferentes modos, embora possam ser agrupados em função da dicotomia pessoal vs. social (Mueller \& Wornhoff, 1990; Rokeach, 1973). Schwartz (1990), não obstante, indica que existem valores que não exatamente podem ser expressos como reproduzindo esta oposição; este autor pensou então em valores mistos. Gouveia (1998) reforça esta idéia, propondo a existência de valores centrais, que são compatíveis com os pessoais e os sociais. Provavelmente, esta nova terminologia contribua a esclarecer a relação dos valores com os construtos individualismo e coletivismo, que será tratada a seguir.

\section{O Individualismo-Coletivismo e os Valores Humanos}

Em vários estudos se tentou estabelecer a relação do individualismo e coletivismo com os valores humanos, predominando as abordagens exploratórias e estritamente empíricas (ver Gouveia \& Vidal, 1998). Alguns autores apenas especulam quais são os valores individualistas e coletivistas, sem levar em consideração uma teoria como referência, ou recopilam categorias normativas em relação a um padrão cultural específico (Gouveia, 2001). Os que partem de um modelo teórico dos valores não apresentam uma medida direta do individualismo e coletivismo ou tratam a medida efetuada como uma pontuação única ou como duas pontuações definidas a partir da mediana (Ex.: Ros \& Gómez, 1997). Diante disso, pode-se dizer que apesar da clara conexão teórica entre os valores e o individualismo e coletivismo, as relações entre estes construtos não têm sido testadas empiricamente de modo sistemático, sendo uma lacuna presente na literatura que reclama por novas contribuições (Oishi, Schimmack, Diener \& Suh, 1998).

Em um estudo realizado por Ros e Gómez (1997), correlacionou-se a Escala de Individualismo e Coletivismo de Triandis, que mede a dimensão individualista, com o Questionário de Valores de Schwartz. Verificou-se que as pontuações da escala de Triandis se correlacionaram de modo estatisticamente significativo $(p<0,01)$ e positivo com os valores poder $(r=0,37)$, realização $(r=0,18)$ e hedonismo $(r=0,20)$, que atendem a interesses individualistas, e inversamente com benevolência $(r=-0,25)$, que cumpre a interesses coletivistas. Sua correlação também foi negativa com universalismo $(r=-0,27)$, um tipo motivacional que expressa interesses mistos. Contrariamente ao esperado, os tipos motivacionais autodireção, estimulação e tradição não apresentaram correlações estatisticamente significativas com esta medida, o mesmo sendo observado para os valores de segurança, que cumprem interesses mistos.

Em função da mediana da medida de Triandis, Ros e Gómez (1997) criaram duas pontuações para diferenciar os sujeitos com individualismo baixo (alocentrismo) e alto (idiocentrismo). A propósito, coerentemente com o modelo de Schwartz, observaram correlação direta e significativa $(p<0,01)$ do alocentrismo com os valores de benevolência $(r=0,78)$ e tradição $(r=0,75)$, e do idiocentrismo com poder $(r=0,77)$, hedonismo $(r=0,63)$ e estimulação $(r=0,64)$. Os valores com interesses mistos, universalismo e seguranç, correlacionaramse tanto com o alocentrismo ( $r=0,37$ e 0,51 , respectivamente) quanto com o idiocentrismo ( $r=0,24$ e 0,42 , respectivamente). Conformidade, embora teoricamente cumpra a interesse coletivista, correlacionou-se direta e significativamente com estas duas pontuações ( $r=0,81$ e 0,24 , respectivamente). Do mesmo modo, realização e autodireção se correlacionaram ao mesmo tempo com o alocentrismo $(r=0,30$ e 0,67 , respectivamente) e o idiocentrismo. ( $r=0,17$ e 0,37 , respectivamente), apesar destes serem valores teoricamente individualistas.

Oishi e colaboradores (1998) compararam diretamente os modelos de Schwartz e Triandis. Para isso usaram três medidas de valores (Schwartz Value Survey, Painvise Comparison Value Survey e Personal Striving Value Survey). Considerando estas medidas, observaram que o individualismo vertical apresentou correlação positiva e significativa $(p<0,01)$ com os valores poder ( $r=0,52 ; 0,54$ e 0,45 ; respectivamente) e realização ( $r=0,43 ; 0,43$ e 0,33 ; respectivamente). $\mathrm{O}$ individualismo horizontal o fez somente com o valor autodireção $(r=0,33$; $p<0,01 ; r=0,19$ e $0,18, p<0,05$, respectivamente). O coletivismo vertical foi significativamente $(p<0,01)$ correlacionado com tradição $(r=0,25 ; 0,40$ e 0,38 , respectivamente) e conformidade 
( $r=0,37 ; 0,42$ e 0,40 , respectivamente). Já o coletivismo horizontal o fez somente com o valor de benevolência $(r=0,37 ; 0,42 \mathrm{e}$ 0,40 ; respectivamente; $p<0,01$ para todos).

Segundo Gouveia (2001), é possível identificar valoreschave em Schwartz que correspondem às dimensões de Triandis. Assim, o individualismo horizontal é sinônimo de autodireção, enquanto que o vertical expressa os valores realização e poder, por outro lado, o coletivismo horizontal se define pelos valores benevolência e seguranç, enquanto que o atributo vertical o faz com conformidade e tradição. Este autor acrescenta ainda que, embora valores como riqueza, poder social e autoridade sirvam a interesses individualistas, estes também tendem a receber prioridade em nações coletivistas; os valores individualistas não são necessariamente mais predominantes em nações individualistas do que em coletivistas e viceversa (ver também Oishi \& cols., 1998).

Em um dos primeiros estudos com amostra brasileira, verificou-se que os valores básicos poder e êxito se correlacionaram direta e significativamente $(p<0,01) \mathrm{com}$ o individualismo vertical ( $r=0,33$ e 0,14 , respectivamente); autodireção e privacidade apresentaram correlações positivas e significativas $(p<0,001)$ com o individualismo horizontal $(r=0,21$ e 0,29 , respectivamente); obediência e tradição o fizeram com o coletivismo vertical ( $r=0,27$ e 0,20, respectivamente; $p<0,001$ para ambos); e, por último, apoio social e convivência apresentaram o mesmo padrão de correlações com o coletivismo horizontal ( $r=0,32$ e 0,26, respectivamente; $p<0,001$ para ambos) (Maia, Gouveia, Silva Filho, Milfont \& Andrade, 2001).

Comparando os resultados de pesquisas que utilizaram os modelos de Schwartz e Triandis, observam-se divergências principalmente em relação aos atributos do individualismo. Por exemplo, enquanto que na amostra de Oishi e colaboradores (1998) o valor poder esteve correlacionado negativamente com o individualismo horizontal $(r=-0,21, p<0,01)$, na pesquisa empreendida por Gouveia (2001) estes construtos se correlacionaram diretamente $(r=0,28, p<0,001)$. A mesma discrepância foi observada quanto ao valor autodireção. No estudo dos primeiros autores sua correlação foi negativa com o individualismo vertical ( $r=-0,23, p<0,01)$, porém foi positiva na pesquisa do último autor antes citado $(r=0,16$, $p<0,01)$. Neste sentido, poder-se-ia afirmar que existe um consenso sobre um conjunto específico de valores que descrevem o coletivismo (Gouveia, 2001; Oishi \& cols., 1998; Ros \& Gómez, 1997), todavia, o mesmo não ocorre com o individualismo.

Diante do exposto, faz-se necessário reafirmar os objetivos do presente estudo. Pretende-se conhecer os valores humanos que melhor descrevem as dimensões do individualismo e coletivismo previamente descritas, bem como avaliar a adequação de tratar estes construtos a partir da dicotomia de valores pessoais e sociais.

\section{Método}

\section{Participantes}

Participaram do presente estudo 304 pessoas, membros da população geral e estudantes do ensino médio e universitário. A amostra foi intencional. Consideram-se aquelas pessoas que, uma vez contatadas, aceitaram fazer parte do estudo. A maioria dos participantes foi do sexo feminino $(62,5 \%)$, solteiro $(67,4)$, católico $(71,5 \%)$, tendo cursado o ensino médio $(52,2 \%)$. A idade média destes foi de 29 anos $(d p=16,01)$, variando de 13 a 88 anos. $\mathrm{Na}$ dificuldade de se obter amostras aleatórias, procurou-se reunir participantes que assegurassem o máximo de dispersão necessária em variáveis como idade e atividade ocupacional.

\section{Instrumentos}

Os participantes responderam um questionário constando de três partes:

Escala Multi-Fatorial de Individualismo e Coletivismo. Elaborada e validada por Gouveia, Andrade, Jesus, Meira e Formiga (2002), esta escala está composta por 30 itens, compreendendo atitudes e/ou opiniões, eqüitativamente distribuídos entre as seis dimensões de que tratam esta medida (com exemplos de itens entre parênteses): protoindividualismo (É essencial para mim satisfazer minhas necessidades básicas; Tenho medo de não ter amanhã o que possuo hoje); individualismo expressivo (Para realizar-me, minha profissão tem que ser conhecida e admirada; Prefiro aproveitar o lado divertido da vida do que ficar reivindicando direitos); individualismo horizontal (Minhas decisões não são influenciadas pelos demais; Gosto de ter um espaço íntimo, só meu); individualismo vertical (Vencer é tudo; Os meus planos para o futuro estão acima de qualquer coisa); coletivismo horizontal (Quando agridem algum membro da minha família, sinto-me agredido; Minha felicidade depende daqueles que me rodeiam) e coletivismo vertical (Deveria ser ensinado às crianças colocar o dever antes do prazer; No trabalho ou estudo sempre obedeço as ordens dos meus superiores). Tais itens são respondidos em escala de sete pontos, com os seguintes extremos: 1=Discordo Totalmente e $7=$ Concordo Totalmente. Os autores deste instrumento apresentam seus parâmetros psicométricos; uma análise fatorial confirmatória indicou a aceitabilidade da sua estrutura fatorial, composta por seis dimensões $\left(\chi^{2} /\right.$ g.l. $=2,38$, $A G F I=0,85$ e RMSE $A=0,07)$.

Questionário dos Valores Básicos. Instrumento elaborado e validado por Gouveia (1998), está composto por 24 itens ou valores específicos, respondidos em uma escala 
com nove pontos. Inicialmente pede-se ao respondente que leia atentamente e responda em uma escala de sete pontos, com os extremos 1=Nada importante e 7=Muito importante, $\mathrm{O}$ grau de importância de cada um dos valores; uma vez respondidos, o participante terá que indicar aquele que considera o mais importante de todos, e a seguir o menos importante de todos, os quais recebem os escores 8 e 0 , respectivamente. Estes 24 valores são agrupados em três categorias, segundo o critério de orientação psicossocial: pessoal, central e social.

Lista de Perguntas Sócio-Demográficas. Os participantes responderam a um conjunto de perguntas sobre características pessoais (Ex.: sexo, idade, estado civil, etc.), e também, atributos sócio-econômicos (Ex.: grau de religiosidade, renda familiar).

\section{Procedimento}

Os aplicadores foram orientados para dar as mesmas instruções, seguindo um procedimento padrão. Isso visava garantir um mínimo de respostas enviesadas. As instruções enfatizavam como responder a escala, pedindo-se que as respostas fossem dadas individualmente e que não deixassem nenhum item em branco. A aplicação dos instrumentos foi realizada em sala de aula, no caso dos colégios e universidades, ou nas residências das pessoas, quando estas provinham da população geral. Com exceção da lista de características sócio-demográficas, os dois outros instrumentos foram intercalados, procurando evitar o efeito de exposição da informação. O tempo médio para responder os instrumentos foi de aproximadamente 20 minutos.

\section{Resultados}

Com a finalidade de caracterizar o tipo de orientação assumido pelos participantes deste estudo, compararam-se suas médias para cada uma das dimensões do individualismo e coletivismo. Em termos gerais, os participantes se mostraram mais coletivistas $(m=25,8, d p=4,02)$ do que individualistas $(m=21,7, d p=3,65), t(241)=14,33, p<0,001$; estas duas medidas se correlacionaram direta e significativamente entre si $(r=0,35, p<0,001)$. Considerando seus fatores específicos, procedeu-se a uma $M A N O V A$ para medidas repetidas, tendo sido observado diferenças estatisticamente significativas entre estes (Lambda de Wilks $=0,24, F=152,95, p<0,001)$. Em ordem crescente, as médias dos fatores foram as seguintes: individualismo vertical ( $m=20,6)$, individualismo expressivo $(m=20,6)$, coletivismo vertical $(m=22,2)$, individualismo horizontal $(m=22,3)$, protoindividualismo $(m=23,4)$ e coletivismo horizontal $(m=29,4)$.
Como próximo passo, atendendo ao objetivo de conhecer o padrão de correlação entre os valores humanos e as dimensões do individualismo e coletivismo, foram calculadas as correlações ( $r$ de Pearson) entre tais construtos. A propósito, calcularam-se também os coeficientes de correlação parcial, controlando a pontuação total dos participantes nos valores humanos. Os resultados são apresentados na Tabela 1.

Como pode ser observado, o individualismo se correlacionou positiva e significativamente $(p<0,001)$ com os valores pessoais, tanto no caso da correlação total $(r=0,55)$ como da parcial $\left(r_{\text {parcial }}=0,35\right)$. No caso do coletivismo, este apresentou o mesmo padrão de correlações com os valores sociais $\left(r=0,57 ; r_{\text {parcial }}=0,45\right)$. No que se a refere às correlações do individualismo e coletivismo com as funções psicossociais, verificaram-se os seguintes resultados:

Individualismo. Correlacionou-se com os valores de realizaça $\tilde{c}_{\text {( }} r=0,55 ; r_{\text {parcial }}=0,35 ; p<0,001$ para ambos), destacandose os valores específicos prestígio $\left(r=0,41, p<0,001 ; r_{\text {parcial }}=0,28\right.$, $p<0,01)$ e poder $\left(r=0,33, p<0,001 ; \quad r_{\text {parcial }}=0,21, p<0,01\right)$, e com a função psicossocial experimentação $(r=0,37, p<0,001$; $\left.r_{\text {parcial }}=0,15, p<0,05\right)$, especificamente com os valores prazer $\left(r=0,32, p<0,001 ; r_{\text {parcial }}=0,16, p<0,05\right)$ e emocão $(r=0,23, p<0,001$; $\left.r_{\text {parcial }}=0,16, p<0,05\right)$. Embora sua correlação com os valores sociais tenha sido inicialmente positiva $(r=0,18, p<0,01)$, demonstrou-se ser inversa quando se controlou a pontuação total dos valores humanos $\left(r_{\text {parcial }}=-0,32, p<0,001\right)$. Este mesmo padrão de correlação foi observado para os valores normativos ( $r=0,16 ; r_{\text {parcial }}=-0,19 ; p<0,05$ para ambos) e interacionais $\left(r=0,14, p<0,05 ; r_{\text {parcial }}=-0,33, p<0,001\right)$. Os valores centrais apresentaram uma correlação direta e significativa com o individualismo $(r=0,30, p<0,001)$, tendo esta sido próxima a zero quando se controlou a pontuação total dos valores humanos $(r=-0,12, p>0,05)$.

Coletivismo. Correlacionou-se direta e significativamente com os valores normativos $\left(r=0,58 ; r_{\text {parcial }}=0,47 ; p<0,001\right.$ para ambos), principalmente com obediência $\left(r=0,55 ; r_{\text {parcial }}=0,44\right.$; $p<0,001$ para ambos) e religiosidade $\left(r=0,47 ; r_{\text {parcial }}=0,39\right.$; $p<0,001$ para ambos), e com os valores interacionais $(r=0,38$, $\left.p<0,001 ; r_{\text {parcial }}=0,17, p<0,05\right)$, sobretudo com afetividade $\left(r=0,14 ; r_{\text {parcial }}=0,13 ; p<0,05\right.$ para ambos) e convivencia $(r=0,30$, $p<0,001)$. Sua correlação foi nula com os valores pessoais $(r=0,05, p>0,05)$. Não obstante, quando se controlou a pontuação total dos valores humanos, tal correlação foi significativa e inversa $\left(r_{\text {parcial }}=-0,37, p<0,001\right)$, reproduzindose este padrão para os valores de experimentação $\left(r_{\text {parcial }}=-0,35\right.$, $p<0,001)$ e realização $\left(r_{\text {parcial }}=-0,20, p<0,05\right)$. No que se refere à categoria de valores centrais, o coletivismo se correlacionou significativa $(p<0,001)$ e positivamente com estes valores $(r=0,26)$, embora tal correlação tenha sido próxima a zero quando se controlou a pontuação total 
Tabela 1

Correlação do Individualismo e Coletivismo com os Valores Humanos

\begin{tabular}{|c|c|c|c|c|}
\hline \multirow[b]{3}{*}{ Valores Pessoais } & \multicolumn{2}{|c|}{ Individualismo } & \multicolumn{2}{|c|}{ Coletivismo } \\
\hline & $r$ & $r_{\text {parcial }}$ & $r$ & $r_{\text {parcial }}$ \\
\hline & $0,55^{* * *}$ & $0,35^{* * *}$ & 0,05 & $-0,37 * * *$ \\
\hline Experimentação & $0,37 * * *$ & $0,15^{*}$ & $-0,05$ & $-0,35^{* * *}$ \\
\hline Emoção & $0,23^{* * *}$ & $0,16^{*}$ & $-0,10$ & $-0,19^{*}$ \\
\hline Estimulação & 0,09 & $-0,16^{*}$ & $0,13^{*}$ & $-0,07$ \\
\hline Prazer & $0,32 * * *$ & $0,16^{*}$ & $-0,01$ & $-0,21 * *$ \\
\hline Sexual & $0,15^{*}$ & 0,07 & $-0,08$ & $-0,18^{*}$ \\
\hline Realização & $0,55^{* * *}$ & $0,35^{* * *}$ & $0,13^{*}$ & $-0,20 *$ \\
\hline Exito & $0,26^{* * *}$ & 0,07 & $0,15^{*}$ & $-0,00$ \\
\hline Poder & $0,33^{* * *}$ & $0,21 * *$ & $0,12^{*}$ & 0,02 \\
\hline Prestígio & $0,41 * * *$ & $0,28 * * *$ & $0,22 * * *$ & 0,02 \\
\hline Autodireção & 0,10 & $-0,07$ & $-0,07$ & $-0,23 * * *$ \\
\hline Privacidade & $0,28^{* * *}$ & $0,15^{*}$ & $-0,06$ & $-0,25 * * *$ \\
\hline Valores Sociais & $0,18^{* *}$ & $-0,32 * * *$ & $0,57 * * *$ & $0,45^{* * *}$ \\
\hline Normativos & $0,16^{*}$ & $-0,19^{*}$ & $0,58^{* * *}$ & $0,47 * * *$ \\
\hline Obediência & 0,12 & $-0,13$ & $0,55^{* * *}$ & $0,44 * * *$ \\
\hline Religiosidade & $0,15^{*}$ & $-0,04$ & $0,47 * * *$ & $0,39 * * *$ \\
\hline Tradição & 0,08 & $-0,14^{*}$ & $0,40 * * *$ & $0,27 * * *$ \\
\hline Ordem social & 0,08 & $-0,18^{*}$ & 0,11 & $-0,02$ \\
\hline Interacionais & $0,14^{*}$ & $-0,33 * * *$ & $0,38^{* * *}$ & $0,17 *$ \\
\hline Afetividade & 0,06 & $-0,15^{*}$ & $0,14^{*}$ & $0,13 *$ \\
\hline Apoio social & $0,12 *$ & $-0,26 * * *$ & $0,30 * * *$ & 0,06 \\
\hline Convivência & 0,09 & $-0,18^{*}$ & $0,30 * * *$ & 0,11 \\
\hline Honestidade & 0,09 & $-0,09$ & $0,15^{*}$ & 0,06 \\
\hline Valores Centrais & $0,30^{* * *}$ & $-0,12$ & $0,26^{* * *}$ & $-0,04$ \\
\hline Existência & $0,24 * * *$ & $-0,11$ & $0,38^{* * *}$ & $0,15^{*}$ \\
\hline Estabilidade pessoal & $0,14^{*}$ & $-0,09$ & $0,26 * * *$ & 0,09 \\
\hline Saúde & 0,07 & $-0,13^{*}$ & $0,27 * * *$ & $0,13^{*}$ \\
\hline Sobrevivência & $0,26 * * *$ & 0,05 & $0,24 * * *$ & 0,04 \\
\hline Suprapessoais & $0,23 * * *$ & $-0,05$ & 0,06 & $-0,16^{*}$ \\
\hline Justiça social & $-0,03$ & $-0,11$ & $-0,08$ & $-0,10$ \\
\hline Conhecimento & $0,30 * * *$ & 0,07 & $0,16^{* *}$ & $-0,03$ \\
\hline Beleza & 0,09 & $-0,02$ & $-0,07$ & $-0,16^{*}$ \\
\hline Maturidade & $0,24 * * *$ & $-0,05$ & $0,26^{* * *}$ & 0,05 \\
\hline
\end{tabular}

Notas: $* p<0,05, * * p<0,01, * * * p<0,001$. O $r_{\text {parcial }}=$ controlou-se a pontuação total dos valores humanos.

dos valores humanos $\left(r_{\text {parcial }}=-0,04, p>0,05\right)$. Entre os valores centrais, destacaram-se aqueles de existencia $(r=0,38$, $\left.p<0,001 ; r_{\text {parcial }}=0,15, p<0,05\right)$.

Em resumo, observou-se que o individualismo pode ser caracterizado por uma maior adesão aos valores pessoais, enquanto que o coletivismo expressa uma ênfase nos valores sociais. Este resultado se mantém consistente, mesmo tendo controlado a pontuação total dos valores humanos. Tal controle, não obstante, implica pensar nas dimensões do individualismo e coletivismo como opostas entre si. Este aspecto precisará ser discutido oportunamente. No presente estudo, não obstante, parece mais justificável não seguir exercendo este controle, permitindo comparar os resultados obtidos com pesquisas prévias.

Levando em conta o antes comentado, o seguinte passo das análises estatísticas foi correlacionar os valores com as dimensões específicas do individualismo e coletivismo, como apresentado na Tabela 2. 
Tabela 2

Correlação das Dimensões do Individualismo e Coletivismo com os Valores Humanos Básicos

\begin{tabular}{|c|c|c|c|c|c|c|}
\hline & IV & $I H$ & $P I$ & $I E$ & $C V$ & $\mathrm{CH}$ \\
\hline Valores Pessoais & $0,45 * * *$ & $0,22 * *$ & $0,39 * * *$ & $0,47 * * *$ & 0,10 & $-0,02$ \\
\hline Experimentação & $0,28 * * *$ & $0,15^{* *}$ & $0,28^{* * *}$ & $0,27 * * *$ & $-0,05$ & $-0,04$ \\
\hline Emoção & $0,15^{*}$ & $0,16^{* *}$ & $0,14^{*}$ & $0,15^{* *}$ & $-0,07$ & $-0,11$ \\
\hline Estimulação & 0,12 & $-0,01$ & 0,08 & 0,08 & $0,13^{*}$ & 0,09 \\
\hline Prazer & $0,26 * * *$ & $0,19 * * *$ & $0,25^{* * *}$ & $0,28^{* * *}$ & $-0,04$ & 0,02 \\
\hline Sexual & 0,09 & 0,03 & $0,14^{*}$ & 0,07 & $-0,11$ & $-0,03$ \\
\hline Realização & $0,45^{* * *}$ & $0,21 * * *$ & $0,37 * * *$ & $0,50 * * *$ & $0,19 * *$ & 0,03 \\
\hline Exito & $0,22^{* * *}$ & 0,06 & $0,16^{* *}$ & $0,16^{* *}$ & $0,13^{*}$ & $0,13^{*}$ \\
\hline Poder & $0,36 * * *$ & 0,05 & $0,18^{* *}$ & $0,27 * * *$ & $0,15^{* *}$ & 0,02 \\
\hline Prestígio & $0,34 * * *$ & 0,08 & $0,29 * * *$ & $0,45^{* * *}$ & $0,27 * * *$ & 0,09 \\
\hline Autodireção & 0,04 & $0,18^{* *}$ & 0,05 & 0,05 & $-0,08$ & $-0,00$ \\
\hline Privacidade & $0,14^{*}$ & $0,18^{* *}$ & $0,24 * * *$ & $0,29 * * *$ & $-0,04$ & $-0,08$ \\
\hline Valores Centrais & $0,21 * *$ & 0,09 & $0,28^{* * *}$ & $0,19 * *$ & $0,20 * * *$ & $0,28^{* * *}$ \\
\hline Existência & $0,23 * * *$ & $-0,08$ & $0,35^{* * *}$ & $0,17 * *$ & $0,30 * * *$ & $0,37 * * *$ \\
\hline Estabilidade pessoal & $0,15^{*}$ & $-0,08$ & $0,21 * * *$ & 0,10 & $0,20 * * *$ & $0,23 * * *$ \\
\hline Saúde & 0,11 & $-0,07$ & $0,19 * *$ & 0,05 & $0,19 * * *$ & $0,33 * * *$ \\
\hline Sobrevivência & 0,20 *** & $-0,01$ & $0,31^{* * *}$ & $0,21 * * *$ & $0,22 * * *$ & $0,16^{* *}$ \\
\hline Suprapessoais & $0,12^{*}$ & $0,18^{* *}$ & $0,12 *$ & $0,13^{*}$ & 0,06 & 0,11 \\
\hline Justiça social & $-0,07$ & $0,12^{*}$ & $-0,08$ & $-0,08$ & $-0,12^{*}$ & 0,07 \\
\hline Conhecimento & $0,22 * * *$ & 0,03 & $0,20 * * *$ & $0,25^{* * *}$ & $0,13^{*}$ & $0,17 * *$ \\
\hline Beleza & $-0,00$ & $0,21 * * *$ & 0,01 & 0,03 & $-0,01$ & $-0,08$ \\
\hline Maturidade & $0,22 * * *$ & $-0,02$ & $0,22 * * *$ & $0,17 * *$ & $0,21 * *$ & $0,22 * * *$ \\
\hline Valores Sociais & $0,15^{*}$ & $-0,10$ & $0,23^{* *}$ & 0,10 & $0,50 * * *$ & $0,49 * * *$ \\
\hline Normativos & $0,17 * *$ & $-0,13^{*}$ & $0,18^{* *}$ & 0,08 & $0,52^{* * *}$ & $0,47 * * *$ \\
\hline Obediência & $0,16^{* *}$ & $-0,17 * *$ & $0,19 * *$ & 0,04 & $0,52 * * *$ & $0,38^{* * *}$ \\
\hline Religiosidade & 0,09 & $-0,04$ & $0,12^{*}$ & $0,13^{*}$ & $0,38^{* *}$ & $0,40^{* *}$ \\
\hline Tradição & $0,15^{*}$ & $-0,16^{* *}$ & 0,09 & 0,04 & $0,37 * * *$ & $0,28^{* * *}$ \\
\hline Ordem social & 0,04 & 0,04 & 0,11 & $-0,01$ & 0,10 & $0,18^{* *}$ \\
\hline Interacionais & 0,07 & $-0,04$ & $0,22 * * *$ & 0,09 & $0,31 * * *$ & $0,36^{* * *}$ \\
\hline Afetividade & 0,01 & $-0,01$ & 0,03 & $-0,02$ & 0,06 & $0,25^{* * *}$ \\
\hline Apoio social & 0,04 & $-0,03$ & $0,22 * * *$ & 0,10 & $0,25^{* * *}$ & $0,25^{* * *}$ \\
\hline Convivência & 0,07 & $-0,05$ & $0,16^{* *}$ & 0,05 & $0,25^{* * *}$ & $0,24 * * *$ \\
\hline Honestidade & 0,05 & 0,03 & 0,11 & 0,08 & $0,17 * *$ & $0,12^{*}$ \\
\hline
\end{tabular}

Notas. ${ }^{*} p<0,05 ; * * p<0,01 ; * * * p<0,001$. Identificação dos fatores: $I V=$ Individualismo Vertical; $I H=$ Individualismo Horizontal; $P I=$ Protoindividualismo; $I E=$ Individualismo Expressivo; $C V=$ Coletivismo Vertical; $C H=$ Coletivismo Horizontal.

A partir dos resultados foram selecionados os valores que, segundo a literatura, estariam mais correlacionados com tais dimensões. O padrão de correlação encontrado é resumido como segue:

Individualismo Vertical. Como esperado, esta dimensão se correlacionou diretamente com os valores pessoais $(r=0,45$, $p<0,001)$, principalmente com aqueles de realização $(r=0,45$, $p<0,001)$. Entre tais valores, sua correlação foi mais forte compoder $(r=0,36, p<0,001)$ e prestígio $(r=0,34, p<0,001)$.

Individualismo Horizontal. Sua correlação com os valores pessoais foi também direta e estatisticamente significativa $(r=0,22, p<0,001)$, sendo mais forte com os valores de realização $(r=0,21, p<0,001)$. Do conjunto de tais valores, 
as correlações maiores foram com privacidade e autodireção $(r=0,18, p<0,01$; para ambos).

Protoindividualismo. Esta medida se correlacionou direta e significativamente com os valores pessoais $(r=0,39, p<0,001)$ e centrais $(r=0,28, p<0,001)$. Embora sua correlação tenha sido mais forte com os valores de realização $(r=0,37, p<0,001)$, esta foi também significativa com aqueles de existência $(r=0,35$, $p<0,001)$, o que era teoricamente esperado. Os valores desta função psicossocial com os quais mais se correlacionou o protoindividualismo foram: sobrevivência $(r=0,31, p<0,001) \mathrm{e}$ estabilidade pessoal $(r=0,21, p<0,001)$.

Individualismo Expressivo. Este tipo de individualismo se correlacionou direta e significativamente com os valores pessoais ( $r=0,47, p<0,001)$, destacando-se principalmente os valores de realização $(r=0,50, p<0,001)$. No conjunto de tais valores, esta dimensão se correlacionou mais fortemente com prestígio $(r=0,45, p<0,001)$ e privacidade $(r=0,29, p<0,001)$. O valor prazer, que figura entre aqueles de experimentação, apresentou a terceira correlação mais forte com o individualismo expressivo $(r=0,28, p<0,001)$.

Coletivismo Vertical. Esta dimensão se correlacionou direta e significativamente com os valores sociais $(r=0,50$, $p<0,001)$, destacando-se a função psicossocial de valores normativos $(r=0,52, p<0,001)$. Especificamente, sua correlação se deu de maneira mais forte com os valores específicos de obediência $(r=0,52, p<0,001)$ e religiosidade $(r=0,38, p<0,001)$.

Coletivismo Horizontal. Sua correlação foi direta e significativa com os valores sociais $(r=0,49, p<0,001)$, principalmente com a função psicossocial de valores normativos $(r=0,47, p<0,001)$. Entre tais valores, as correlações mais fortes foram com religiosidade $(r=0,40, p<0,001) \mathrm{e}$ obediência $(r=0,38, p<0,001)$. O valor afetividade $(r=0,25$, $p<0,001)$, pertencente a função psicossocial denominada de interacional, apresentou correlação significativa com esta dimensão, o que permite diferenciá-la da anterior.

Em resumo, percebe-se que as dimensões do individualismo e coletivismo podem ser correlacionadas de modo diferenciado com certos valores básicos, permitindo identificar um tipo específico de orientação social. Estes resultados precisam ser entendidos à luz da literatura sobre tais construtos.

\section{Discussão}

Apesar da tradição dos estudos sobre o individualismo e o coletivismo no âmbito da Psicologia Social TransCultural (Kagitçibasi \& Berry, 1989), as pesquisas a respeito no Brasil estão apenas começando. Segundo Hofstede (1984), este é um país coletivista; a Paraíba, de acordo com Gouveia (1998), é um dos estados mais coletivistas no Brasil, tendência que é confirmada aqui, corroborando outro estudo anteriormente realizado com uma amostra paraibana (Maia \& cols., 2001). No entanto, ao contrário do que sugere Triandis (1995), parece que o atributo horizontalé mais evidenciado do que o vertical, questionando-se a visão de extrema obediência à autoridade como característica dos brasileiros, segundo descreve este autor. Mas este não é o único aspecto que permite repensar os dados da literatura. Previamente havia sido sugerida a predominância do individualismo ou do coletivismo como orientação social adotada pelas pessoas em determinada cultura (Triandis), como se fossem categorias excludentes. Não obstante, os resultados aqui descritos evidenciaram que estas estão direta e significativamente correlacionadas entre si, sugerindo que podem coexistir, como também apontam outros autores (Schwartz, 1990; Sinha \& Tripathi, 1994).

Quanto ao objetivo principal deste estudo, embora existam atualmente alguns estudos correlacionando o individualismo-coletivismo com os valores humanos em outras culturas (Gouveia, 1998, 2001; Ros \& Gómez, 1997) e mesmo no Brasil (Maia \& cols., 2001), nada era até então conhecido sobre a relação do protoindividualismo e do individualismo expressivo com tais valores. Neste sentido, o presente estudo representa uma contribuição. Pretendeu igualmente superar a simples classificação de valores individualistas, coletivistas e mistos (Schwartz, 1990), que previamente se mostrou ineficaz (Gouveia, 1998; Ros \& Gómez, 1997), procurando conhecer precisamente quais valores são mais típicos destas dimensões, oferecendo uma compreensão normativa do individualismo e coletivismo.

\section{Valores Descritores do Individualismo}

O individualismo vertical se correlacionou com os valores poder, prestígio e êxito, corroborando estudos empreendidos anteriormente (ver Gouveia, 2001; Maia \& cols., 2001; Oishi \& cols., 1998; Triandis, 1996). Isso sugere que o individualista orientado verticalmente seria o indivíduo que visa o êxito, sendo dotado possivelmente de atitudes mais instrumentais, podendo almejar cargos de chefia e de destaque, querendo ser eficiente naquilo que se dispõe a fazer, sentindo também a necessidade de ser admirado e reconhecido socialmente. Com base na correlação com a função psicossocial realização, também verificada no estudo empreendido por Oishi e colaboradores (1998), pode-se dizer que individualistas verticais seriam aqueles indivíduos que buscam alcançar metas estabelecidas, nutrindo sentimentos de competitividade.

O individualismo horizontal se correlacionou com os valores de autodireção e privacidade, reforçando a idéia de Triandis (1995) de que o atributo principal deste tipo de orientação é um ser único. Este resultado foi também 
observado em estudos prévios (Maia \& cols., 2001; Oishi \& cols., 1998). Assim, pode-se dizer que o individualista orientado horizontalmente é o indivíduo que preza por uma liberdade incondicional, desejando se sentir livre para ir e vir, e agir de acordo com sua própria vontade.

O protoindividualismo se correlacionou com os valores de sobrevivência e estabilidade, evidenciando o perfil de pessoas que se preocupam em saciar as suas necessidades básicas, de ter amanhã aquilo que possui hoje (ver Triandis, 1995). Uma orientação que é claramente materialista (Inglehart, 1991). A partir da correlação positiva e significativa com o critério psicossocial de existência, pode-se dizer que o protoindividualista seria aquele que se preocupa em garantir sua própria existência orgânica.

O individualismo expressivo se apresentou correlacionado com os valores prestígio e prazer, indicando um perfil de pessoas que querem desfrutar da vida, satisfazendo seus desejos e vontades, pretendendo também ser reconhecidas naquilo que fazem. Como assinala Parsons (1959/1976), tais indivíduos almejam ser reconhecidos, destacar-se dos demais, aproveitar as oportunidades para se diferenciar e expressar. A correlação com as funções psicossociais de realização e experimentação indica que estes, embora dêem importância ao lazer e divertimento, também buscam realizações e uma identidade própria.

\section{Valores Descritores do Coletivismo}

O coletivismo vertical apresentou correlação positiva e significativa com os valores de tradição, obediência e religiosidade, corroborando resultados encontrados anteriormente (ver Maia \& cols., 2001; Oishi \& cols., 1998), sobretudo, no que diz respeito ao primeiro destes valores. Assim, pode-se dizer que os coletivistas que se orientam verticalmente, são pessoas que buscam seguir normas sociais, cumprindo suas atividades e deveres.

O coletivista horizontal, embora tenha se correlacionado mais fortemente com os valores normativos, também o fez diretamente com aqueles interacionais, especificamente com apoio social, afetividade e convivência. A partir destes resultados, pode-se dizer que os coletivistas orientados horizontalmente são pessoas que dão importância ao fato de fazerem parte de grupos sociais ou religiosos, providenciando e obtendo ajuda, prezando pelas relações afetivas, não querendo se sentir sozinhos (Triandis, 1995). Estes, provavelmente, não se resignam a renunciar suas metas em relação a todas as pessoas, e sim apenas a seu endogrupo.

Em resumo, os resultados sugerem que o coletivismo, sobretudo o vertical, não se limita a valores de orientação social. Concretamente, o coletivismo vertical se correlacionou com a função psicossocial de valores de realização, entre eles, os valores específicos prestígio, poder e êxito. Isto era esperado, segundo Ros e Gómez (1997). A relação de valores de competência e êxito pessoal tanto pode ser buscada por pessoas individualistas quanto por coletivistas, já que possivelmente o sucesso das pessoas pode beneficiar os indivíduos bem como o seu grupo de pertença ou, ainda, toda a sociedade. Por outro lado, o individualismo parece se limitar mais a valores de orientação pessoal. A dimensão horizontal se correlacionou inversamente com valores normativos, no entanto, as correlações positivas e significativas do individualismo vertical com os valores de obediência e tradição podem sugerir uma necessidade de se adequar, ainda que de maneira superficial, a grupos com a finalidade de conseguir atingir metas pessoais.

Nas pesquisas realizadas anteriormente (Gouveia, 2001; Oishi \& cols., 1998), que utilizaram os modelos de Schwartz e Triandis, observam-se divergências, sobretudo em relação aos atributos do individualismo. Por exemplo, enquanto na amostra de Oishi e colaboradores o valor poder esteve correlacionado negativamente com o individualismo horizontal, na pesquisa empreendida por Gouveia sua correlação foi direta. O mesmo ocorreu com o valor autodireção, correlacionado-se inversamente com o individualismo vertical na pesquisa dos primeiros autores e positivamente na pesquisa do último. Aqui, estes valores aparecem relacionados positivamente tanto com o individualismo vertical quanto horizontal, embora só seja significativa a correlação do valor poder com individualismo verticale do valor autodireção com o individualismo horizontal.

Parece evidente aqui a existência de um padrão de convergência entre os valores que atendem a uma orientação pessoal e o individualismo; o mesmo ocorrendo entre os que atendem a uma orientação sociale o coletivismo. Não obstante, a dicotomia de valores pessoais vs. sociais não é suficiente para entender estes dois tipos de orientação social. Por exemplo, os valores centrais, principalmente os de existência, são fundamentais para compreender o protoindividualismo. É também relevante destacar que sua função psicossocial suprapessoal, especificamente os valores de beleza e maturidade, contribuem para definir a dimensão individualismo horizontal.

Finalmente, como os valores se revelam proeminentes para compreender diferenças tanto individuais (Gouveia, 1998; Schwartz, 1992) como culturais (Hofstede, 1984), espera-se que as novas dimensões propostas (protoindividualismo e individualismo expressivo), próprias de culturas latinas, como o Brasil, suscitem pesquisas futuras que visem compreender antecedentes e conseqüentes das orientações sociais assumidas pelas pessoas. Como em pesquisa prévia (Maia \& cols., 2001), esta cultura se mostrou claramente coletivista. Neste sentido, valeria igualmente a pena o esforço por incorporar novas dimensões que ajudassem a caracterizar os aspectos emics do coletivismo brasileiro, que seguramente não é equivalente àquele observado em culturas orientais (ver Triandis, 1995). 


\section{Referências}

Braithwaite, V. A. \& Scott, W. A (1991). Values. Em J. P. Robinson, P. R.

Shaver \& L. S. Wrightsman (Org.), Measures of personality and social psychological attitudes (pp. 661-753). San Diego, CA: Academic Press.

Gouveia, V. V. (1998). La natureza de los valores descriptores del individualismo y del colectivismo: Una comparación intra e intercultural. Tese de Doutorado nãopublicada, Departamento de Psicologia Social, Universidade Complutense de Madri. Madri, Espanha.

Gouveia, V. V. (2001). El individualismo y el colectivismo normativo:

Comparación de dos modelos. Em M. Ros \& V. V. Gouveia (Orgs.), Psicología social de los valores humanos: Desarrollos teóricos, metodológicos y aplicados (pp. 101122). Madri: Editorial Biblioteca Nueva.

Gouveia, V. V., Andrade, J. M. de, Jesus, G. R. de, Meira, M. \& Formiga, N. S. (2002). Escala Multi-Fatorial de Individualismo e Coletivismo: Elaboração e validação de construto. Psicologia: Teoria e Pesquisa, 18, 203-212.

Gouveia, V. V. \& Clemente, M. (1998). La medida del individualismo y del colectivismo: La investigación en el campo de la Psicología Cultural. La Coruña, Espanha: Editorial Universidad de La Coruña.

Gouveia, V. V., Clemente, M. \& Espinosa, P. (no prelo). The horizontal and vertical attributes of individualism and collectivism: Replication of the Singelis et al's study in Spain. The Journal of Social Psychology.

Gouveia, V. V., Clemente, M. \& Vidal, M. A. (1998). España desde dentro:

$\mathrm{El}$ individualismo y el colectivismo como rasgos diferenciadores de las comunidades autónomas. Sociedade y Utopia, 11, 168-179.

Gouveia, V. V. \& Vidal, M. A. (1998). Los valores en los soldados profesionales. Em M. Clemente, A. Parrilla \& M. A. Vidal (Orgs.), Psicología jurídica y cuerpos de seguridad (pp. 547-574). Madri: Fundación Universidad-Empresa.

Hofstede, G. (1984). Culture's consequences: International differences in work-related values. Beverly Hills, CA: Sage.

Inglehart, R. (1991). El cambio cultural en las sociedades industriales avanzadas. Madri: Centro de Investigaciones Sociológicas/Siglo XXI.

Kagitçibasi, Ç. (1997). Individualism and collectivism. Em J. W. Berry, M. H. Segall \& Ç. Kagitçibasi (Orgs.), Handbook of cross-cultural psychology: Social behavior and applications (Vol. 3, pp. 1-49). Boston: Allyn and Bacon.

Kagitçibasi, Ç. \& Berry, J. W. (1989). Cross-cultural psychology: Current researches and trends. Annual Review of Psychology, 40, 493-531.

Maia, L., Gouveia, V. V., Silva Filho, S. B., Milfont, T. L. \& Andrade, M. W. C. L. de (2001). Prioridades valorativas e individualismo-coletivismo: Padrões de convergência. PSICO, 33, 7-24.

Markus, H. R. \& Kitayama, S. (1991). Culture and the self: Implications for cognition, emotion and motivation. Psychological Review, 98, 224-253.

Maslow, A. H. (1970). Motivation and personality. New York: Harper \& Row. (Original publicado em 1954)

Molpeceres, M. A. (1994). El sistema de valores: Su configuración cultural y su socialización familiar en la adolescencia. Tese de Doutorado não-publicada, Faculdade de Psicologia, Universidade de Valência. Valência, Espanha.

Mueller, D. J. \& Wornhoff, S. A. (1990). Distinguishing personal and social values. Educational and Psychological Measurement, 50, 691-699.

Oishi, S., Schimmack, U., Diener, E. \& Suh, E. M. (1998). The measurement of values and individualism-collectivism. Personality and Social Psychology Bulletin, 24,1177-1189.
Parsons, T. (1976). El sistema social. Madri: Revista de Occidente. (Original publicado em 1959)

Rokeach, M. (1973). The nature of human values. New York: Free Press.

Ros, M. \& Gómez, A. (1997). Valores personales individualistas y colectivistas y su relación con la autoestima colectiva. Revista de Psicología Social, 12, 179-198.

Schwartz, S. H. (1990). Individualism-collectivism: Critique and proposed refinements. Journal of Cross-Cultural Psychology, 21, 139-157.

Schwartz, S. H. (1992). Universals in the content and structure of values: Theoretical advanced and empirical tests in 20 countries. Em M. Zanna (Org.), Advanced in experimental social psychology (Vol. 25, pp. 1-65). Orlando, FL: Academic Press.

Schwartz, S. H. (1994). Are there universal aspects in the structure and contents of human values? Journal of Social Issues, 50, 19-45.

Schwartz, S. H. \& Bilsky, W. (1987). Toward a universal psychological structure of human values. Journal of Personality and Social Psychology, 53, 550-562.

Schwartz, S. H. \& Bilsky, W. (1990). Toward a theory of the universal content and structure of values: Extensions and cross-cultural replications. Journal of Personality and Social Psychology, 53, 878-891.

Schwartz, S. H. \& Huismans, S. (1995). Value priorities and religiosity in four Western religions. Social Psychology Quarterly, 58, 88-107.

Schwartz, S. H., Verkasalo, M., Antonovsky, A. \& Sagiv, L. (1997). Value priorities and social deseability: Much substance, some style. British Journal of Social Psychology, 36, 3-18.

Singelis, T. M., Triandis, H. C., Bhawuk, D. S. \& Gelfand, M. J. (1995). Horizontal and vertical dimensions of individualism and collectivism: A theoretical and measurement refinement. Cross-Cultural Research, 29, 240275.

Sinha, D. \& Tripathi, R. C. (1994). Individualism in a collectivist culture: A case of coexistence of opposites. Em U. Kim, H. C. Triandis, Ç. Kagitçibasi, S.-C. Choi \& G. Yoon (Orgs.), Individualism and collectivism: Theory, method, and applications (pp. 123-136). Thousand Oaks, CA: Sage.

Triandis, H. C. (1993). Collectivism and individualism as cultural syndromes. Cross-Cultural Research, 27, 155-180.

Triandis, H. C. (1995). Individualism and collectivism. Boulder, CO: Westview Press.

Triandis, H. C. (1996). The psychological measurement of cultural syndromes. American Psychologist, 51, 407-415.

Triandis, H. C., Chen, X. P. \& Chan, D. K. -S. (1998). Scenarios for the measurement of collectivism and individualism. Journal of Cross-Cultural Psychology, 29, 275-289.

Triandis, H. C. \& Gelfand, M. J. (1998). Converging measurement of horizontal and vertical individualism and collectivism. Journal of Personality and Social Psychology, 74, 118-128.

Triandis, H. C., McCusker, C. \& Hui, C. H. (1990). Multimethod probes of individualism and collectivism. Journal of Personality and Social Psychology, 59, 1006-1020

Sobre os autores

Valdiney V. Gouveia é Doutor em Psicologia Social. Professor da Pós-Graduação (Mestrado e Doutorado) em Psicologia Social da Universidade Federal da Paraíba.

Josemberg Moura de Andrade é Mestrando em Psicologia Social da Universidade de Brasília.

Taciano Lemos Milfont é Professor da Universidade Federal de Alagoas. É Doutorando em

Psicologia Social da Universidade de Auckland, Nova Zelândia.

Fabiana Queiroga é Graduada em Psicologia pela Universidade Federal da Paraíba.

Walberto Silva dos Santos é Mestrando em Psicologia Social na Universidade Federal da Paraíba. 